\title{
Virtual inertia support for wind turbine system
}

\author{
Nor Shahida Hasan ${ }^{1}$, Norzanah Rosmin ${ }^{2}$, Nor Julia Mohd Nordin ${ }^{3}$, Aede Hatib Mustaamal ${ }^{4}$, \\ Siti Maherah Husin ${ }^{5}$, Aripriharta ${ }^{6}$, Ira Devi Sara ${ }^{7}$ \\ ${ }^{1,2,5}$ Centre of Electrical Energy System (CEES), Sekolah Kejuruteraan Elektrik, Fakulti Kejuruteraan, Malaysia \\ ${ }^{3,6}$ Department of POWER, School of Electrical Engineering, Engineering Faculty, \\ Universiti Teknologi Malaysia, Malaysia \\ ${ }^{4}$ School of Education, Faculty of Social Sciences and Humanity, Universiti Teknologi Malaysia, Malaysia \\ ${ }^{6}$ Department of Electrical Engineering, Universitas Negeri Malang, Indonesia \\ ${ }^{7}$ Department of Electrical Engineering and Computer, Syiah kuala Universiti, Indonesia
}

\begin{tabular}{l}
\hline \hline Article Info \\
\hline Article history: \\
Received Jun 7, 2019 \\
Revised Aug 10, 2019 \\
Accepted Aug 24, 2019
\end{tabular}

Keywords:

Frequency nadir

ROCOF

Supercapacitor

Virtual inertia support

Wind turbine

\section{Corresponding Author:}

Norzanah Rosmin,

\begin{abstract}
Previously, a conventional synchronous generator is adapted into the wind energy conversion system to supply the required inertial support; however its slow behaviour may worsening the stability problem of the system during frequency event. In this paper, a new approach that enables virtual inertial support from supercapacitor during sudden load increase e.g. when wind turbine experiencing sudden wind or load changes is presented. Here, a new approach that can regulate the system frequency by controlling the charging and discharging process of supercapacitor is demonstrated. Hence, an algorithm on how to derive the behavior of supercapacitor and power converter is presented. From the simulation results, it has been found that this proposed approach successfully reduces the frequency nadir and ROCOF of the system frequency. It also able to avoid the second frequency dips during frequency recovery time.
\end{abstract}

Copyright $\odot 2020$ Institute of Advanced Engineering and Science. All rights reserved.

Department of POWER, School of Electrical Engineering,

Universiti Teknologi Malaysia,

81310 Skudai, Johor, Malaysia.

Email: norzanah@utm.my

\section{INTRODUCTION}

In recent years, wind energy had shown a great development in its generation system [1]. Integrating variable speed wind turbine into the grid system can reduce the frequency response and power damping capability of wind turbine. This reduction can increase the power difference between supply and load side and also could increase the initial rate of change of frequency (ROCOF) [2, 3]. If the value of ROCOF increased beyond of its threshold value, it may trigger the operation of protection relays of system inertial support (such as synchronous generator (SG)). This occasion can cause the SG to trip and leads to cascading failure in the system. Detail explanation of the cascading failure in frequency response during low inertia system is carried out in [4]. SG is one of the existing frequency supports system that had been employed in wind energy conversion system (WECS) for years [4-6]. During power unbalance between supply and load, SG will release or absorb its stored kinetic energy to prevent transient frequency change. However, due to its slow response in providing inertial support during frequency event, better inertial support which also known as virtual inertial supports (VIS) that mimics the behaviour of SG are widely proposed.

VISs are the non SG inertial support which controlled to improve the frequency of the system. Researchers keep on improving the performance of such VIS to ensure the improved VIS can give fast response during frequency deviation, fast recovery time, enough inertial support and reduce mechanical 
stress of generator. Currently, there are different types of VIS which widely been implemented in WECS, namely, rotating mass, DC-link capacitor [7-9] and energy storage [10-13].

In rotating mass, the kinetic energy, (KE) is stored in rotor of wind turbine and normally it will be controlled using active power filter (APC). There are supplement loops and gains involved in this method which increased its complexity and operating time, particularly when considering large scale wind power system [14]. In fact, the stored and released kinetic energy is totally depends on the available wind blow. This situation will degrade the system inertial support during underproduction wind speed. This APC also can increase the mechanical stress of the generator because it will divert the maximum power point tracking (MPPT) wind generator to its inertial support curves. Conversely, in VIS based DC link capacitor; the KE support during frequency deviation will be extracted or absorbed by the DC-link capacitor [5]. The charging and discharging process of DC-link capacitor will be controlled to merge with the frequency change. Unfortunately, the main drawback of this method is its energy sized. This capacitor must be large enough to provide temporary inertial response during frequency disturbance. In energy storage, (ES) based VIS, similar charging and discharging concept as DC-link capacitor is applied. The difference is in their storage characteristics, such as power and energy density, life cycle and capital cost. Not all ESs are applicable for VIS [15]. For VIS application, ESs must have high power density to give fast response during frequency change. Also, high energy density to provide endless inertial support in any sudden frequency change and low capital cost to develop cost-effective inertial support [11]. Another inertial supports which non SG which also applicable for WECS is using offshore wind farm [8]. By regulating DC-link voltage and frequency control of full converter wind turbine, effective inertial response is successfully provided without any extra investment. The huge problem in this proposed method is its involvement of large scale wind turbine. This is not applicable for small scale wind turbine.

Hence, in order to avoid mechanical stress on generator system, enlarge DC link size and slow response time during frequency event, this research proposed energy storage to mimic the behaviour of SG to provide VIS during frequency event. For VIS application, the ESs must have high power density to give fast response during frequency change. Thus, supercapacitor, $(\mathrm{SC})$ is chosen in this research to provide limitless VIS, as SC provides high density of power capability, fast response in charging and discharging [16], and also has longer life time [17]. The propose approach aims to improve the control technique of SC by regulating its charging an discharging process based on every second change of frequency. This aim helps to increase the SC performance regardless how sudden the load change. Several publications on implementation of SC as VIS can be found in [13,18,19]. To summarise, this paper presents the ability of SC acts as VIS in wind turbine system operation. A simple but fast VIS can be supplied to the wind turbine system when there is fluctuating of wind speeds and also from the load side. An algorithm that derive the relationship the SC and the power converter is demonstrated. This then solving the problem of second frequency dip in the operational system.

\section{PROPOSED VIRTUAL INERTIAL SUPPORT IN WIND TURBINE SYSTEM}

Figure 1 illustrates the schematic diagram of the tested system. In this research, approximately $23 \%$ wind penetration level, $(3 \mathrm{MW}, 575 \mathrm{~V})$ is employed to study the effectiveness of supercapacitor (SC), in providing virtual inertial support (VIS) especially during sudden load change. This analysis is done under constant $10 \mathrm{~m} / \mathrm{s}$ wind speed condition. A detailed model of wind PMSG system is used as a test system. The rotor side converter (RSC) and grid side converter (GSC) is controlled based on PWM vector control to control the generated wind power and maintain the DC link voltage, $(1200 \mathrm{~V})$ at its rated value respectively. Detail explanation on both control systems can be found in [5]. The (SC) is bounded to the DC link through a bidirectional DC/DC converter. Here, the synchronous generator (SG) acts as grid system with the rating of 10MVAR, $13.8 \mathrm{kV}$ and its governor permanent drop of 4\% [5]. The AC common coupling voltage in this paper is set to $25 \mathrm{kV}$. L1 consists of a fixed load as 7MW+0.7MVAR and other additional load which enters the network at second of 50 is set to be $0.7 \mathrm{MW}+0.07 \mathrm{MVAR}$. The size of the additional load which is $10 \%$ less than the fixed load is based on [5]. The buck boost converter controls charging and discharging state of SC. This state is controlled based on frequency change. If the measured frequency more than $60 \mathrm{~Hz}$, the S1 will on, while S2 off, then the converter acts as a buck to charge the SC. Meanwhile, if the measured frequency less than $60 \mathrm{~Hz}$, the S1 will off, while S2 on, then the converter acts as a boost to provide VIS to the network [20]. The size of SC is modelled 50\% less than DC link voltage [21]. 


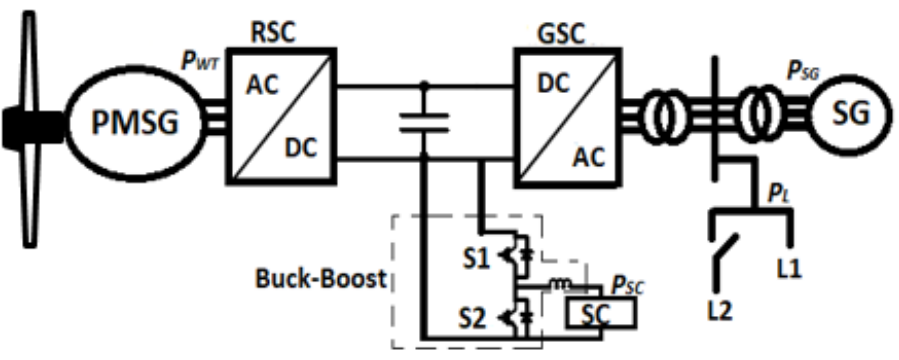

Figure 1. Schematic diagram of tested system

\section{DERIVATION OF SUPERCAPACITOR AND BUCK BOOST CONVERTER}

The SC acts as a power balancer between wind power, $P_{W T}$, SG power, $P_{S G}$, and load power, $P_{L}$. Theoretically, the proposed VIS is formulated based on inertia virtual rotating mass and DC link capacitor from [5]. Instead of extracting the inertial support from DC-link capacitor and rotating mass which required the DC-link to upgrade its size, the SC is proposed here to provide limitless inertial support. The implementation of SC in supplying the inertial support had been carried out in several publications $[13,18,19,22]$. However, in this research, a new approach in obtaining the reference value of SC voltage is introduced based on the change of frequency. This is because; the imbalance power between load and generation will change the dynamic behaviour of system frequency. The mathematical expression of wind power, $P_{W T}$, is expressed as in (1). As shown in (2) expressed the relationship of all the power involved in Figure 1 to serve the load L1 and L2. Where $\rho$ is the air density, $r$ is the rotor blade radius of the wind turbine, $v_{w}$ is the wind speed, $C \mathrm{p}$ is the power coefficient, $P_{S C}$ is the power absorb by the SC [23, 24].

$$
\begin{aligned}
& P_{W T}=0.5 \rho \pi r^{2} v_{w}^{3} C_{p} \\
& P_{W T}+P_{S G}-P_{S C}-P_{L}=0
\end{aligned}
$$

As shown in (3) expressed the mechanical inertial response in providing VIS from SG [5]. Where $\mathrm{H}$ is the $\mathrm{SG}$ inertia constant, $\mathrm{f}$ is the system frequency and $\Delta P$ is the power difference between input mechanical power and output electrical power of SG

$$
2 H f \frac{d f}{d t}=\Delta P
$$

Thus, by considering similar behaviour of the power difference between input and output of SG, $\Delta P$, the (2) can be derived as (4-5).

$$
P_{W T}+P_{S G}-P_{L}=P_{S C}
$$

Let the total input power of the network as $P_{T}$. Thus, $P_{T}-P_{L}=P_{S C}$ becomes,

$$
\Delta P=P_{S C}
$$

The SC power can also be expressed as:

$$
P_{S C}=i_{S C} v_{S C}=c_{S C} v_{S C} \frac{d v_{S C}}{d t}
$$

Therefore, by (3, 5 and 6), the VIS extraction from SC can be expressed as in (7).

$$
c_{S C} v_{S C} \frac{d v_{S C}}{d t}=2 H_{S C} f \frac{d f}{d t}
$$

By integrating both side, it will get 


$$
\frac{c_{s c}\left(v_{s c}^{2}-v_{s c 0}^{2}\right)}{2}=H_{s c}\left(f^{2}-f_{0}^{2}\right)
$$

where $v_{S C 0}$ and $f_{O}$ is the nominal values for SC voltage and system frequency respectively. Therefore, to obtain new reference value of SC voltage, $v_{S C}^{*}$, As shown in (8) can be linearized around its equilibrium point, as in (9). Then, the control process is rearranged into (13).

$$
c_{s c} v_{s c 0} \Delta v_{s c}=2 H_{s c} f_{0} \Delta f
$$

Thus, the amount of virtual inertial support from SC can be expressed as:

$$
\begin{aligned}
& H_{s c}=\frac{K_{s c} C_{s c} V_{s c 0}}{2 f_{0}} \\
& v_{s c}{ }^{*}=K_{s c} \Delta f+v_{s c 0} \\
& \Delta f=f_{0}-f
\end{aligned}
$$

where $i_{S C}, v_{S C}$ and $c_{S C}$ are the current, voltage and capacitance of the super capacitor. Since $K_{S C}$ is the control parameter of SC to supply the inertial support, thus this value is set using try and error method. As the $K_{S C}$ decreased, the system frequency drop during system disturbance becomes shorter. Thus, 2 is the best value for this analysis [5].

Total power difference between supply and load, $P_{T}$ is summed up with inertial power. The inertial power is consists of inertial response of SG and speed governor response of SG, as in $(13)[13,24]$. Then, these total power will be divided with new SC voltage from (11) to obtained amount of current, $i_{s c}$ to be released or absorbed by SC, which as stated as in (14).

$$
\begin{aligned}
& P_{\text {inertial }}=K_{H} \frac{d \Delta f}{d t}+K_{d r o o p} \Delta f \\
& i_{s c}=\frac{P_{\text {total }}}{v_{s c}^{*}}
\end{aligned}
$$

where $K_{H}$ and $K_{\text {droop }}$ is the coefficient for droop and inertial control. Commonly $K_{H}$ will be set twice as the inertia constant of the WECS [13].

Then, the inertial power and total power difference between supply and load will be divided with the new SC voltage to obtain related SC current. These current will be converted into PWM to switch the buck boost converter either to charge or discharge the SC. Here, the SC rated voltage is set to be $50 \%$ of DC link voltage, which is $600 \mathrm{~V}$. Its rated capacitance is $100 \mathrm{~F}$, ESR is $15 \mathrm{~m} \Omega$, number of series capacitors are 223 , initial voltage is $550 \mathrm{~V}$ and operating temperature is $25^{\circ} \mathrm{C}$. The value of equivalent series resistance, ESR, rated capacitance and rated voltage is obtained from Maxwell Technologies Ultra capacitor datasheet [26].

\section{RESULTS AND DISCUSSIONS}

Schematic diagram on Figure 1 is modelled and tested using MATLAB/Simulink software to verify the effectiveness of the proposed approach in providing VIS during sudden load change. In this test system, an additional load is added at second of 50. Then, at this time, the SC is regulated to inject a certain amount of power to reduce the frequency nadir and ROCOF of the system frequency. The injected power is based on power difference between WT, SG powers with load power. A constant $14 \mathrm{~m} / \mathrm{s}$ wind speed is applied throughout the simulation times.

Figure $2(a, b)$ shows the measured system frequency and ROCOF with and without the presents of SC. It is observed that, with the presence of SC, during sudden load increase, the frequency nadir of the system frequency improve from $58.2 \mathrm{~Hz}$ to $59.1 \mathrm{~Hz}$. Similar behaviour can be seen in evaluating the ROCOF. 
In this research, during sudden load change, the SG will generate excess power to accommodate the demand. Thus, by improving the frequency nadir of the system frequency, means, the additional mechanical power to run the SG during frequency change will decrease compared to without SC. In fact, with the presences of SC, the overshoot signal of the system frequency (at initial state) is also reduced from approximately $63.31 \mathrm{~Hz}$ to $62.3 \mathrm{~Hz}$. Besides, with SC, the frequency signal reach its steady state value at second of approximately 68 and remains constant towards the end of simulation time. However without SC, there is second frequency dip occurrence within the seconds of 70 to 80 . This occurrence might be due to the slow response time of the SG after disturbance. Figure 2c shows the state of charge, SOC of SC for 100sec simulation times. Here, the switching signals of buck-boost are controlled by the frequency change. For the first $10 \mathrm{sec}$, since the frequency drop from $60 \mathrm{~Hz}$ to $56 \mathrm{~Hz}$, thus the boost is on to discharge the SC. For the next $10 \mathrm{sec}$, the SC is charging because the value of system frequency is more than $60 \mathrm{~Hz}$. Then, at $50 \mathrm{sec}$, sudden load decrease occurred, the SC acts as boost again to discharge the SC until the end of simulation times. However, the SOC of SC somewhat did not reach the expectation of charging and discharging process. Further critical analysis needs to be done in terms of SOC to avoid the self-discharge and self-charge of SC system.

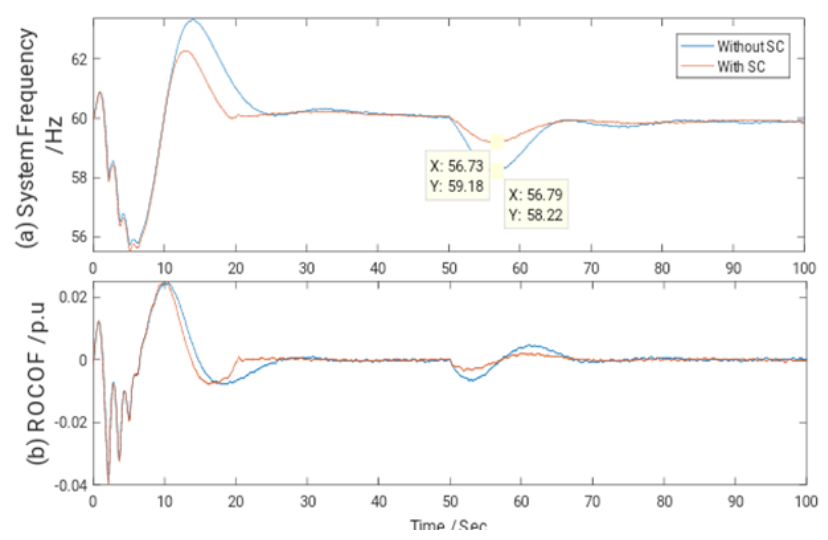

Figure 2. Measured (a) System Frequency, (b) ROCOF and (c) SOC of SC

Figure 3 displays how much power transfer from SG and WT to accommodate the load L1 and L2. The SC did not increase the amount of power received at load. Both measured power at load are the either with or without SC. The SC only affect the dynamic performance of system frequency which as mentioned in Figure 2. As can be seen here, during the first 50 seconds, with SC, the power supplied from wind turbine is lower compared to without SC. This is because; some of the wind power is used to charge the SC. Thus, at this time interval, the excess required power is generated by SG. Afterwards, for the rest 50 seconds, extra power is extracted from SG to accommodate the requirement of $10 \%$ sudden load increase. Further critical analysis in controlling the buck boost converter needs to be done to ensure, the SC and wind turbine can effectively operates within its charging and discharging interval.

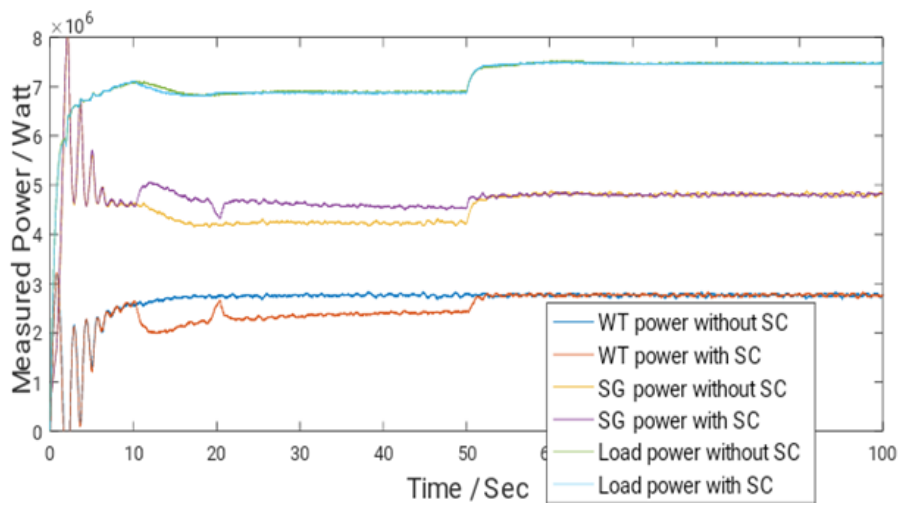

Figure 3. Measured power of wind tubine, synchronous generator and load 
The behaviour of DC link voltage of WT system is illustrated as in Figure 4. This DC link voltage remains constant at its rated value, $1200 \mathrm{~V}$ throughout the entire inertial response. Even though the SC is parallel connected to DC-link voltage, the charging and discharging process of SC did not disturbs the DC link value. This is because; the grid side converter is designed to maintain the DC link voltage during any disturbance.

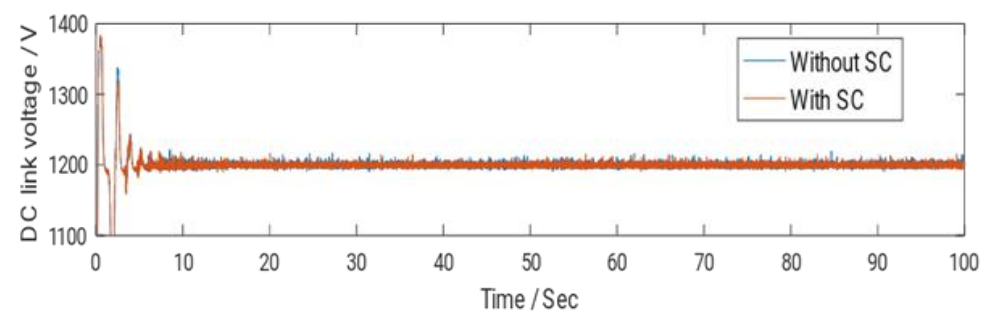

Figure 4. DC link voltage

\section{CONCLUSION}

This paper proposes and analyse a new approach in providing fast virtual inertial support during sudden load change for wind PMSG systems. Detailed design and analyses of the proposed method is conducted using MATLAB Simulink software. The charging and discharging process of SC is controlled to response to every single change of frequency event. It proved that, during sudden load change at second of 50 , the SC not only able to reduce the frequency nadir and ROCOF of the system frequency, but also successfully avoid second frequency dip during frequency recovery process. It can also be seen that, the amount of generated power from WT and SG are depends on the load demand. However, further critical analysis is required in this research to limit the charge and discharge rate of SC.

\section{ACKNOWLEDGEMENTS}

Special thanks to Malaysian Government for the financial support to execute this research (TDR 48.1(06G65), GUP (18H08) and GUP (18H21), ICF (4S142), Centre of Electrical Energy System (CEES), School of Electrical Engineering, Engineering Faculty, UTM and POWER Department, SKE.

\section{REFERENCES}

[1] K. Vidyanandan and N. Senroy, "Issues in the grid frequency regulation with increased penetration of wind energy systems," in Engineering and Systems (SCES), 2012 Students Conference on, 2012, pp. 1-6.

[2] S. Wang, J. Hu, X. Yuan, and L. Sun, "On inertial dynamics of virtual-synchronous-controlled DFIG-based wind turbines," IEEE Transactions on Energy Conversion, vol. 30, pp. 1691-1702, 2015.

[3] AEMO; and ElectraNet. Update to Renewable Energy Integration in South Australia [Online].

[4] N. Modi and R. Yan, "Low inertia power systems: Frequency response challenges and a possible solution," in Power Engineering Conference (AUPEC), 2016 Australasian Universities, 2016, pp. 1-6.

[5] Y. Li, Z. Xu, and K. P. Wong, "Advanced Control Strategies of PMSG-Based Wind Turbines for System Inertia Support," IEEE Transactions on Power Systems, vol. PP, pp. 1-1, 2016.

[6] M. El Mokadem, V. Courtecuisse, C. Saudemont, B. Robyns, and J. Deuse, "Experimental study of variable speed wind generator contribution to primary frequency control," Renewable Energy, vol. 34, pp. 833-844, 2009.

[7] D. Gautam, L. Goel, R. Ayyanar, V. Vittal, and T. Harbour, "Control strategy to mitigate the impact of reduced inertia due to doubly fed induction generators on large power systems," IEEE Transactions on Power Systems, vol. 26, pp. 214-224, 2011.

[8] H. Liu and Z. Chen, "Contribution of VSC-HVDC to frequency regulation of power systems with offshore wind generation," IEEE Transactions on Energy Conversion, vol. 30, pp. 918-926, 2015.

[9] W.-S. Im, C. Wang, W. Liu, L. Liu, and J.-M. Kim, "Distributed virtual inertia based control of multiple photovoltaic systems in autonomous microgrid," IEEE/CAA Journal of Automatica Sinica, 2016.

[10] N. Mendis, S. Sayeef, K. M. Muttaqi, and S. Perera, "Hydrogen energy storage for a permanent magnet wind turbine generator based autonomous hybrid power system," in Power and Energy Society General Meeting, 2011 IEEE, 2011, pp. 1-7.

[11] H. Silva-Saravia, H. Pulgar-Painemal, and J. Mauricio, "Flywheel energy storage model, control and location for improving stability: The Chilean case," IEEE Transactions on Power Systems, 2016. 
[12] G. Delille, B. Francois, and G. Malarange, "Dynamic Frequency Control Support by Energy Storage to Reduce the Impact of Wind and Solar Generation on Isolated Power System's Inertia," IEEE Transactions on Sustainable Energy, vol. 3, pp. 931-939, 2012.

[13] Y. Tan, K. Muttaqi, P. Ciufo, and L. Meegahapola, "Enhanced frequency response strategy for PMSG based wind energy conversion system using ultracapacitor in remote area power supply systems," IEEE Transactions on Industry Applications, 2016.

[14] H. Ye, W. Pei, and Z. Qi, "Analytical modeling of inertial and droop responses from a wind farm for short-term frequency regulation in power systems," IEEE Transactions on Power Systems, vol. 31, pp. 3414-3423, 2016.

[15] A. Islam, S. Nimmagadda, A. Subburaj, and S. B. Bayne, "A Review of Frequency Response Solution for Type-3 Wind Turbines Using Energy Storage Device," International Journal of Renewable Energy Research (IJRER), vol. 6, pp. 1423-1434, 2016.

[16] M.H.A. Malek, F. Mustafa and A. M. Mohd Asry. A battery-less power supply using supercapacitor as energy storage powered by solar, International Journal of Power Electronics and Drive System (IJPEDS), vol. 10 (1), pp 568-574, 2019.

[17] V. J. Nagarajah, H. J. Lee, K.G. Tan and N. Khunprasit. Performance analysis of supercapacitors for transportation Industry, Indonesian Journal of Electrical Engineering and Computer Science (IJEECS), vol. 13 (3), pp. 1031-1038, 2019.

[18] M. F. M. Arani and E. F. El-Saadany, "Implementing Virtual Inertia in DFIG-Based Wind Power Generation," IEEE Transactions on Power Systems, vol. 28, pp. 1373-1384, 2013.

[19] R. Suryana, "Frequency control of standalone wind turbine with supercapacitor," in Telecommunications Energy Conference (INTELEC), 2011 IEEE 33rd International, 2011, pp. 1-8.

[20] B. Karthik and S. Ramamoorthy, "Dc/Dc Converter Design For Super Capacitor And Battery Power Management In Renewable Energy Source Application."

[21] M. Al-Ramadhan and M. Abido, "Design and simulation of supercapacitor Energy Storage System," in International Conference on Renewable Energies and Power Quality (ICREPQ'12), 2012.

[22] L. Miao, J. Wen, H. Xie, C. Yue, and W.-J. Lee, "Coordinated control strategy of wind turbine generator and energy storage equipment for frequency support," IEEE Transactions on Industry Applications, vol. 51, pp. 2732-2742, 2015.

[23] C. Naim and K, Djallel, Wind energy conversion systems based on a DFIG controlled by indirect vector using PWM AND SVM, Int. Journal of Electrical and Computer Engineering (IJECE), vol. 6 (2),pp. 549-559, 2016.

[24] Ammar A. Aldair, Mofeed T. Rashid, Ali F. HalihaL, Mastaneh Mokayef. Modeling of Micro-grid with the consideration of total harmonic distortion analysis, Indonesian Journal of Electrical Engineering and Computer Science (IJEECS), vol. 15(2), pp. 581-592, 2019.

[25] M.R.I, Sheikh, M.M Haque, and M.A, Hossain, Performance of governor system on minimizing frequency fluctuation with wind power generation, Int. Journal of Electrical and Computer Engineering (IJECE), vol. 2 (2),pp. 46-56, 2012.

[26] M. Technologies, "MAXWELL Technologies Ultracapacitor," ed, 2014.

\section{BIOGRAPHIES OF AUTHORS}

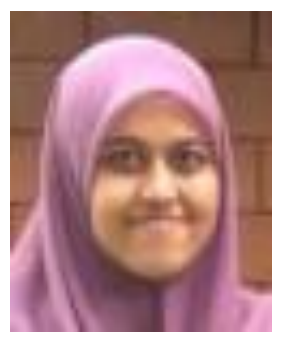

Nor Shahida Hasan is a PhD student at Centre of Electrical Engineering (CEES), School of Electrical Engineering, Universiti Teknologi Malaysia, Johor. She obtained her Bachelor of Electrical Engineering and Master of Electrical Engineering from the same university in 2013 and 2015 respectively. Her research interest is in renewable energy in particular in wind energy system.

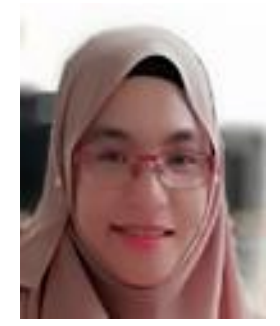

Norzanah Rosmin is a senior lecturer in POWER Department, School of Electrical Engineering, UniversitiTeknologi Malaysia, Johor. She is also a member of Centre of Electrical Engineering (CEES), Institute of Future Energy. She got her Bachelor and Master Degree from Universiti Teknologi Malaysia, meanwhile PhD in Renewable Energy from Loughborough University, United Kingdom in 2015. 


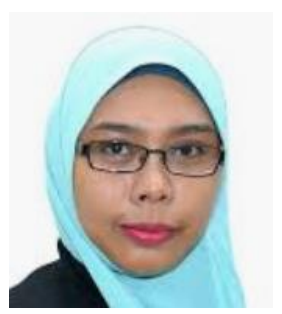

Nor Julia Mohd Nordin is a senior lecturer in POWER Department, School of Electrical Engineering, Universiti Teknologi Malaysia, Johor. Her research interest is in power electronic and electrical machine drive. She obtained her Bachelor, Master and $\mathrm{PhD}$ of Electrical Engineering from Universiti Teknologi Malaysia.

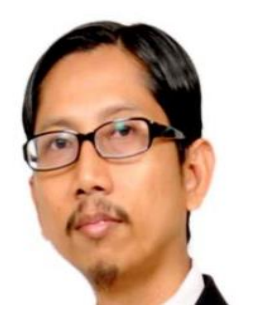

Aede Hatib Mustaamal is an Associate Professor in School of Education, Universiti Teknologi Malaysia. Her main research interest is in creativity and innovation in technical and engineering education.

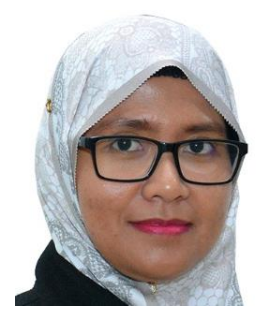

Siti Maherah is a senior lecturer in POWER Department, School of Electrical Engineering, Universiti Teknologi Malaysia, Johor. Her research interest is in power system. She obtained her Bachelor, Master and $\mathrm{PhD}$ of Electrical Engineering from Universiti Teknologi Malaysia.

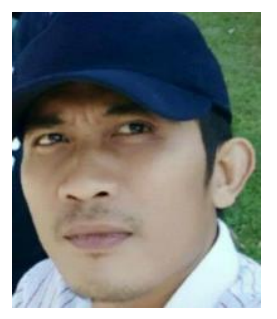

Aripriharta is a Head of Electrical Engineering Program Study, Universiti Negeri Malang (UM), Indonesia. He is also a Chief of Industrial relations of CAMRY on behalf of this university.

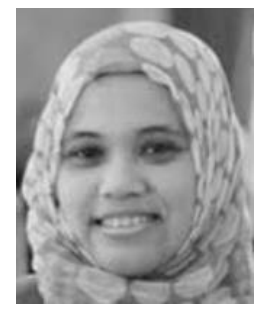

Ira Devi Sara is a lecturer at Electrical Engineering and Computer Department, Syiah Kuala University, Indonesia. She got her PhD from Loughborough University, United Kingdom in 2014. 